\title{
VOLKSSOUVERÄNITÄT UND DEMOKRATIEBEGRIFF IN DER WEIMARER REPUBLIK
}

\section{POPULAR SOVEREIGNITY AND THE CONCEPT OF DEMOCRACY IN THE REPUBLIC OF WEIMAR}

\author{
Oliver Lepsius \\ Universität Münster
}

\begin{abstract}
ZUSAMMENFASSUNG: I. ZUM VERHÄLTNIS VON VOLKSSOUVERÄNITÄT UND DEMOKRATIE.- 1.1. Begriffliche Unterscheidungsbedürftigkeit.- 1.2. Zwei Volksbegriffe.- 1.3. Verfassungsrechtliche Verankerungen.- 1.4. Volkssouveränität und Demokratieprinzip stellen andere Fragen.- 1.5. Demokratie als juristischer oder interdisziplinärer Gegenstand.- II. DIE GEGENSTANDSBESTIMMTE DEMOKRATIEKONZEPTION (CARL SCHMITT).-

2.1. Substantielle Gleichheit.- 2.2. Nicht repräsentierbare Substanz.- 2.3. Parlamentarisch nicht erfüllbare Erwartungen.- 2.4. Schlussfolgerungen.- 2.5. Erklärungsansatz.- III. DAS GEGENSTANDSERZEUGENDEN MODELL (HANS KELSEN).- 3.1. Die Demokratietheorie als Komplementär zur Reine Rechtslehre.3.2. Trennung von Souveränität und Demokratie.- 3.3. Volk und Parlament als unabhängige Staatsorgane.- 3.4. Repräsentation als freiheitssichernder Zurechnungszusammenhang.-IV. ZUSAMMENFASSUNG.
\end{abstract}

Auszug: In der Weimarer Republik wurden grundlegende verfassungstheoretische Debatten geführt. Ein Kernthema war das Verhältnis von Volkssouveränität und Demokratie mit der Frage, wie sich das Volk ausdrücken kann: Unmittelbar oder nur mittelbar über Repräsentanten, mit Hilfe von Organen oder als geistige Ausdrucksform. Es konkurrierten zwei Richtungen, die in dem Aufsatz als die gegenstandsbestimmte und die gegenstandserzeugende Richtung vorgestellt werden. Für die eine wird auf die Schriften von Carl Schmitt zurückgegriffen, für die andere auf das Werk von Hans Kelsen. Beide gehen von entgegengesetzten Demokratie-Konzeptionen aus, die sich insbesondere in den Volksbegriffen und den Funktionen des Volkes als pouvoir constituant (Schmitt) oder pouvoir constitué (Kelsen) unterscheiden. Die zeitgenössischen Differenzen werden zusätzlich durch parallel verlaufende philosophisch-erkenntnistheoretische Kontroversen verschärft: Lässt sich der Volkswille empirisch ermitteln oder nur als geistige Manifestation? Die Weimarer Grundsatzdiskussionen gelten bis heute als eine Gründungsphase westlichen verfassungsrechtlichen Denkens, gewissermaßen die zweite Gründungsphase nach der Revolutionsphase in den USA und in Frankreich vor 1800 .

Abstract: In the Weimar Republic, fundamental debates on constitutional theory were conducted. A core theme was the relationship between popular sovereignty and democracy with the question of how the people could express themselves: Directly or only indirectly through representatives, with the help of organs or as a spiritual form of expression. There competed two directions, which are presented in the essay as the object-determined and the object-generating direction. For one, the writings of Carl Schmitt are used, for the other the work of Hans Kelsen. 
Both start from opposite concepts of democracy, which differ in particular in the popular concepts and the functions of the people as pouvoir constituant (Schmitt) or pouvoir constitue (Kelsen). The contemporary differences are additionally aggravated by philosophical-knowledge-theoretical controversies running in parallel: Can the will of the people be determined em-pirically or only as an intellectual manifestation? To this day, Weimar's fundamental discussions are regarded as a founding phase of Western constitutional thought, the second founding phase, so to speak, after the revolutionary phase in the USA and France before 1800 .

Schlüsselwörter: Volkssouveränität, Verfassungslehre, Demokratie, Repräsentanz, Deutschland, Weimarer Republik.

Keywords: Popular Sovereignty, Constitutional Theory, Democracy, Representation, Germany, Weimar Republic.

Die Weimarer Republik ist eine Zeit grundsätzlicher Auseinandersetzungen um Demokratie, Repräsentation und Volkssouveränität. Das betrifft gerade auch die wissenschaftliche Diskussion. Um 1800 hatte es eine grundsätzliche Debatte um die zentralen Legitimations- und Strukturfragen der Demokratie bereits gegeben: in den USA mit der Begründung der Verfassung durch die Federalist Papers (Hamilton, Madison, Jay) oder in Frankreich mit den revolutionstheoretischen Schriften etwa von Abbé Sieyès. Der Methoden- und Richtungsstreit in der Weimarer Republik stellt den zweiten Begründungsdiskurs modernen westlichen Verfassungsdenkens dar. Die Weimarer Debatten wirken als Bezugspunkt staatstheoretischer Grundfragen bis in die Gegenwart fort. ${ }^{1}$ Zwei Gründe scheinen für die Grundsätzlichkeit und Symbolträchtigkeit vor allem verantwortlich. Zum einen der revolutionäre Wechsel der Souveränitätsgrundlage vom monarchischen Prinzip zur Volkssouveränität ${ }^{2}$ und damit die Frage nach dem Geltungsgrund der Demokratie. Zum anderen dreht es sich in den Weimarer Debatten auch um einen erkenntnistheoretischen Grundkonflikt zwischen einer gegenstandserzeugenden und einer gegenstandsbestimmten Vorgehensweise. ${ }^{3}$ Die dadurch entste-

1 M. Stolleis, Geschichte des öffentlichen Rechts in Deutschland. Dritter Band 1914-1945, 1999, 153-202; C. Gusy, Die Weimarer Reichsverfassung, 1997, 420-455; W. März, Der Richtungs- und Methodenstreit der Staatsrechtslehre, oder der staatsrechtliche Antipositivismus, in: K. W. Nörr/B. Schefold/F. Tenbruck (Hg.), Geisteswissenschaften zwischen Kaiserreich und Republik, 1994, 75-133; R. Smend, Die Vereinigung der deutschen Staatsrechtslehrer und der Richtungsstreit, in: FS Ulrich Scheuner, 1973, 575-589; K. Groh, Demokratische Staatsrechtslehre in der Weimarer Republik, 2010; dies., Die bundesdeutsche Verfassungstheorie in der Tradition der großen Fünf - Preuß, Anschütz, Thoma, Kelsen und Heller, in: U. J. Schröder/A. v. UngernSternberg (Hrsg.), Zur Aktualität der Weimarer Staatsrechtslehre, 2011, 13-35; S.-P- Hwang, Demokratie im Mehrebenensystem, in: Rechtswissenschaft 4 (2013), 166-192; H. Dreier, Staatsrecht in Demokratie und Diktatur, 2016; C. Waldhoff, Folgen - Lehren - Rezeptionen: Zum Nachleben des Verfassungswerks von Weimar, in: H. Dreier/C. Waldhoff (Hrsg.), Das Wagnis der Demokratie. Eine Anatomie der Weimarer Reichsverfassung, 2018, 289-315.

2 Dazu P. Caldwell, Popular Sovereignty and the Crisis of German Constitutional Law, 1997, 112, 85-119; K. Groh, Demokratische Staatsrechtslehre in der Weimarer Republik, 2010, 463 ff.; C. Gusy, 100 Jahre Weimarer Verfassung, 2018, 109 ff.

3 Dazu O. Lepsius, Erkenntnisgegenstand und Erkenntnisverfahren in den Geisteswissenschaften der Weimarer Republik, Ius Commune 22 (1995), 283-310; ders., Die gegensatzaufhebende Begriffsbildung, 1994. 
henden Meinungsverschiedenheiten und Konflikte bestimmen auch die Wahrnehmung und Einschätzung der Demokratie in der Weimarer Republik. ${ }^{4}$

\section{ZUM VERHÄLTNIS VON VOLKSSOUVERÄNITÄT UND DEMOKRATIE}

\subsection{Begriffliche Unterscheidungsbedürftigkeit}

Demokratie bedeutet Volksherrschaft. Volksherrschaft kann sowohl ein Rechtsbegriff als auch eine politische oder geisteswissenschaftliche Kategorie sein. ${ }^{5}$ Volksherrschaft ist nicht deckungsgleich mit Volkssouveränität. Beide werden oft miteinander gleichgestellt, sind jedoch voneinander zu trennen. Souveränität meint Bindungslosigkeit, völlig freies Handlungsvermögen. Sie muss folglich dem Recht vorausliegen, denn Recht führt immer zu einer Form der Bindung. Recht und Souveränität sind folglich Antipoden.

Deswegen kann die Volkssouveränität der Geltungsgrund der Verfassung und infolgedessen auch der Demokratie sein. Als Geltungsgrund der Verfassung entzieht sich der Begriff der Volkssouveränität einer spezifisch verfassungsrechtlichen Bestimmung. Die Volkssouveränität bezieht sich als Begriff auf die Entstehung des Rechts. Sie ist also eine juristische Kategorie und kann dennoch kein Rechtsbegriff im engeren Sinne sein. Volkssouveränität kann letztlich nur außerrechtlich bestimmt werden, denn faßte man sie als Rechtsbegriff auf, machte man die Geltung und Entstehung des Rechts von ihm selbst abhängig. Dann aber wäre nicht das Volk souverän, sondern die Rechtsordnung. ${ }^{6}$ Umgekehrt gilt, dass der Begriff der Volkssouveränität in dem Moment entbehrlich wird, in dem eine Rechtsordnung entstanden ist. Wie die Volkssouveränität rechtlich umgesetzt und durchgesetzt wird, ist keine Frage der Volkssouveränität, sondern der Verfassungsordnung. Eine Errungenschaft des modernen Verfassungsstaates ist es, dass die Souveränitätsfrage nicht mehr gestellt werden braucht und als verfassungsrechtliche Frage nicht mehr gestellt werden kann. Die Souveränitätsfrage hat sich erledigt, solange die verfaßte Rechtsordnung in Kraft bleibt. „Volkssouveräne Entscheidungen" würden die Verfassungsordnung zerstören. Auf die Volkssouveränität können sich nur revolutionäre Neuschöpfungen stützen.

Von der Volkssouveränität zu scheiden ist der Demokratiebegriff des Verfassungsrechts. Demokratie wird zu einem Rechtsbegriff, der die ausgeübte Volkssouveränität voraussetzt. Die Volkssouveränität installiert die Verfassung (Geltungsgrund); die Verfassung installiert die Demokratie (Herrschaftsform). Volkssouveränität und Demokratie haben also begrifflich nichts miteinander zu tun. Das Problem ist jedoch, dass beide in der allgemeinen Rhetorik aufeinander bezogen und miteinander vermischt werden, weil beide Begriffe auf das Wort „Volk“

${ }^{4}$ Dazu K. Sontheimer, Antidemokratisches Denken in der Weimarer Republik, 1968 (1962), 6392 zur Staatsrechtslehre; W. Durner, Antiparlamentarismus in Deutschland, 1997, $92-127$ zur Weimarer Republik.

5 Zur verfassunggebenden Gewalt des Volkes E.-W. Böckenförde, Die verfassunggebende Gewalt des Volkes - ein Grenzbegriff des Verfassungsrechts, in: Staat, Verfassung, Demokratie, 1991 (1986), 90-114; P. Häberle, Zur gegenwärtigen Diskussion um das Problem der Souveränität, AöR 92 (1967), 259-287, M. Kriele, Einführung in die Staatslehre, 6. Aufl. 2015, §§ 2, 12f., 15, 31; Aus der Weimarer Zeit vor allem noch H. Heller, Die Souveränität, 1927; ders., Staatslehre, 6. Aufl. 1983 (1934), 276-279.

6 Vgl. H. Kelsen, Das Problem der Souveränität und die Theorie des Völkerrechts, 1920, 2. Aufl. 1928, insbes. §§ 3-9. 
rekurrieren. Das Volk scheint der Urheber beider Kategorien zu sein, so dass der Eindruck einer Verbindung oder Abhängigkeit entstehen kann.

\subsection{Zwei Volksbegriffe}

Doch es kann sich beim Volk der Volkssouveränität und beim Volk des Demokratieprinzips nicht um dasselbe Volk handeln. Das Volk als pouvoir constituant kann kein rechtlich geregeltes Volk sein, also keine Körperschaft, die sich über Staatsangehörigkeit oder Wahlrecht bestimmen lässt. Dieses Volk ist keine normative Größe. Aber auch als empirische Größe ist der pouvoir constituant nicht bestimmbar. Ob ein Volk als pouvoir constuant gehandelt hat, kann nur in der Rückschau bestimmt werden, nämlich wenn diese Menschenmasse, die sich Volk nennt, eine neue Rechtsordnung durchgesetzt hat, wenn sie die Geltung des alten Rechts gebrochen und die Geltung neuen Rechts begründet hat. Nur dann hat das Volk "souverän“ gehandelt, nämlich bindungslos. Der Effekt des Handelns, die Souveränitätsfrage, ist daher notgedrungen eine Frage, die nur ex post beantwortet werden kann. Das verdeutlicht auch die alternative Betrachtung: Scheitert die Menschenmasse mit der Zerstörung des überkommenen und der Durchsetzung neuen Rechts, dann zeigt sich keine Souveränität, sondern nur eine Rebellion, ein Putsch, ein Aufstand. Entweder das Handeln lässt neue Rechtsmäßigkeit entstehen oder es wird als Rechtsbruch kriminalisiert. Das Volk der Volkssouveränität kann daher auch keine empirisch wahrnehmbare Größe sein, sondern ist immer das Ergebnis einer nachträglichen Interpretation revolutionärer Umtriebe. Das Volk der Volkssouveränität ist ein fiktives, ein gedachtes, ein idealisiertes Volk.

Ganz anders verhält es sich mit dem Volk des Demokratieprinzips: Dieses Volk muss durch Recht geregelt werden, es ist eben ein pouvoir constitué: Es besteht aus den Staatsangehörigen, von denen handlungsfähig nur jene mit Wahlrecht sind. Deswegen kann das Volk des Demokratiebegriffs zum Zweitpunkt der Wahl ganz genau nach Kopf und Zahl bestimmt werden, auf einen einzelnen Wähler bezogen. Dieses Volk wird durch Rechtsregeln bestimmt und ist deswegen empirisch wahrnehmbar als Gruppe der Wahlberechtigten.

Um dieses Problem kreisen die Weimarer Debatten: Wie trennt man verfassungsrechtlich pouvoir constituant und pouvoir constitué? Wie kann ein verfassungsrechtlicher Demokratiebegriff bestehen, ohne auf die Volkssouveränität angewiesen zu sein?

\subsection{Verfassungsrechtliche Verankerungen}

Art. 1 Abs. 2 WRV bestimmt: „Die Staatsgewalt geht vom Volke aus. "7 Wiederholt die Verfassung lediglich den Grundsatz der Volkssouveränität, wie er auch in der Präambel zur WRV ausgesprochen ist? Der Wortlaut kann beides meinen: den Grundsatz der Volkssouveränität wie das verfassungsrechtliche Demokratieprinzip. Von der Klärung des Verhältnisses beider hängen jedoch weitreichende Folgen ab. Bezieht man das verfassungsrechtliche Demokratieprinzip als Verfassungsrechtssatz auf die Volkssouveränität, gewinnt der vorrechtliche

7 Dazu C. Gusy, 100 Jahre Weimarer Verfassung, 2018, 115 ff.; G. Lübbe-Wolff, Das Demokratiekonzept der Weimarer Reichsverfassung, in: H. Dreier/C. Waldhoff (Hrsg.), Das Wagnis der Demokratie. Eine Anatomie der Weimarer Reichsverfassung, 2018, 111-150; siehe zeitgenössisch vor allem: R. Thoma, Das Reich als Demokratie, HdStR I, 1930, 186-200. 
Begriff des Volkes die entscheidende Deutungskraft über die Geltung und die Ausgestaltung der Verfassung. Trennt man hingegen zwischen dem vorrechtlichen Volksbegriff der Volkssouveränität und dem verfassungsrechtlichen normativen Volksbegriff des Demokratieprinzips, dann sichert sich die demokratische Legitimation der Verfassungsordnung von vor- und außer-verfassungsrechtlichen Elementen ab. Das erste Modell, in dem Volkssouveränität und Demokratieprinzip aufeinander bezogen sind, fundiert die demokratische Legitimität in einer Seinsordnung, die über einen bei Volkssouveränität und Demokratieprinzip identischen Volksbegriff auf das Verfassungsrecht ausstrahlt, dieses dann aber auch anfällig macht für die politische Relativität des Volksbegriffs. Die Bestimmung des Volkes als dem Recht vorausliegender Seins-Begriff wird zur entscheidenden Frage der Geltung der Verfassungsordnung.

Das zweite Modell, in dem Volkssouveränität und Demokratieprinzip voneinander geschieden werden, fundiert die demokratische Legitimität in einer Sollensordnung, nämlich in der Verfassung und der von ihr ausgestalteten Verfahrensordnung selbst. Der normative Selbstand der Verfassung wird als kontrafaktisches Element betont. Die Geltung der Verfassungsordnung kann nur durch einen volkssouveränen Akt beendet werden, nicht aber durch den Bezug auf die gesellschaftliche Wirklichkeit kontinuierlich überprüft, relativiert und angepaßt werden. Schon an dieser Schaltstelle zeichnen sich politische Implikationen des jeweils beschrittenen Weges ab.

Demokratieprinzip und Volkssouveränität unterscheiden sich maßgeblich bei der Bestimmung des jeweiligen Legitimationssubjektes und Legitimationsobjekts. Folglich unterscheiden sie sich auch bei der Bestimmung des Legitimationsverhältnisses zwischen Subjekt und Objekt. Die Volkssouveränität wirkt von ihrer Anlage her differenzierungsfeindlich; sie ist auf faktische Einheit gerichtet. Das Demokratieprinzip wirkt genau umgekehrt. Es ist konstitutiv differenzierungsbedürftig und auf normative Ausgestaltung gerichtet. Diesen Grundkonflikt der Demokratietheorie veranschaulicht zu haben, ist eine der fortwirkenden Leistungen der Weimarer Staatslehre.

\subsection{Volkssouveränität und Demokratieprinzip stellen andere Fragen}

Das Demokratieprinzip stellt drei Fragen. Erstens: Wer legitimiert? Diese Frage richtet sich darauf, das Legitimationssubjekt Volk zu bestimmen. Ist es eine vorgegebene Größe? Ist es ideell, ethnisch, arithmetisch oder normativ zu bestimmen? Zweitens: Was wird legitimiert? Diese Frage richtet sich darauf, das Legitimationsobjekt Herrschaft zu definieren. Ist eine Person, eine Institution oder eine Handlungsform gemeint? Erst auf der Basis dieser Vorklärungen kann das Organisations- und Legitimationsverhältnis im einzelnen bestimmt werden und die dritte Frage beantwortet werden: Wie wird das Legitimationsverhältnis von Objekt und Subjekt konstruiert? Die drei Grundfragen finden sich im verfassungsrechtlichen Demokratieprinzip wieder: Alle Staatsgewalt [=Legitimationsobjekt] geht [=Legitimationsverhältnis] vom Volke [= Legitimationssubjekt] aus. Das Demokratieprinzip hat also eine komplexe Aufgabe zu bewältigen, für die mehrere konstruktive Wege zur Verfügung stehen.

Anders liegt es bei der Volkssouveränität. Sie beschäftigt sich nur mit dem Legitimationssubjekt, alle anderen Fragen sind für sie zweitrangig. Es kommt für sie allein auf die Ausübung des Volkswillens an. Das Objekt kann nicht festste- 
hen oder juristisch konstruiert werden, denn es ist erst das Ergebnis des schöpferischen Akts des Volkes. Bei der Volkssouveränität stellt sich daher nicht das Problem, ein Verhältnis zwischen legitimierendem Subjekt und legitimierten Objekt herzustellen. Die demokratietheoretische Problematik reduziert sich von drei Problemen auf ein einziges, nämlich die Bestimmung des Volkes und seines souveränen Willens. Volkssouveränität und Demokratieprinzip unterscheiden sich erneut.

Die unterschiedliche Legitimationswirkung von Volkssouveränität und Demokratieprinzip führt zu unterschiedlichen legitimierenden Subjekten, die jedoch beide mit dem Begriff „Volk“ bezeichnet werden. Das Volk der Volkssouveränität legitimiert die Verfassung und entzieht sich der normativen Bestimmung, während das Volk des Demokratieprinzips als verfassungsrechtlich etablierte Größe gerade normativ bestimmt werden muss. Um einen Gedanken wieder aufzugreifen: Das Volk des Demokratieprinzips ist ein juristischer Begriff, während das Volk der Volkssouveränität zwar eine juristisch relevante Kategorie ist, aber keinen juristischen Begriff darstellt. Am Beispiel der jeweiligen Definition des Volkes lässt sich umgekehrt ablesen, welches Volk gemeint ist. Der normative Volksbegriff richtet sich auf das Demokratieprinzip, während der faktische Volksbegriff auf die Volkssouveränität abzielt. Daher ist es erneut wichtig, Demokratieprinzip und Volkssouveränität voneinander zu scheiden, weil es ansonsten gelänge, über den Begriff des Volkes Voraussetzungen und Aufgaben der einen Kategorie mit denen der anderen $\mathrm{zu}$ verwechseln. Die Legitimationsleistung des Demokratieprinzips könnte sonst unter Rückgriff auf die Volkssouveränität ausgehebelt werden.

\subsection{Demokratie als juristischer oder interdisziplinärer Gegenstand}

Ein weiteres Problem tritt hinzu, nämlich das der disziplinären Zugehörigkeit der Demokratietheorie. In ihrer relationalen Komponente ist sie Gegenstand der Rechtswissenschaft. Bei der Ermittlung der substantiellen Voraussetzungen der Demokratie hingegen konkurriert die Rechtswissenschaft mit anderen Disziplinen. Die Fragen, wer zum Volk gehört und was dessen Herrschaft ist, lassen sich nicht nur juristisch, sondern auch soziologisch, sozialpsychologisch oder historisch thematisieren. Auch in der landläufigen Wahrnehmung wird Demokratie nicht als ein genuin staatsrechtliches Phänomen gedeutet, sondern auf alle möglichen Formen menschlichen Zusammenlebens erstreckt. Oft trifft man auf das weitgesteckte Postulat, dass „die Gesellschaft“ demokratisch sein soll. Mit einer solch weiten Fassung der Demokratie geht die Relation von Subjekt und Objekt verloren. Es wird unklar, was organisiert und legitimiert werden soll und es wird unklar, wem die Organisation und Legitimation zugerechnet werden soll. Legitimationssubjekt und Legitimationsobjekt drohen zusammenzufallen. Umgekehrt können die Voraussetzungen der Demokratie über die Bestimmung des Legitimationssubjektes und des Legitimationsobjektes hinaus ausgedehnt werden auf die Voraussetzungen dieser Kategorien selbst. Gefragt wird dann danach, welche Bedingungen erfüllt sein müssen, damit überhaupt von einem Volk als Legitimationssubjekt gesprochen werden kann. Hier wird der Bereich des Juristischen verlassen. Das Recht vermag normativ zu bestimmen, was ein Volk ist oder welche Herrschaftsform legitimiert werden soll, es vermag aber nicht autonom zu sagen, ob diese Voraussetzungen tatsächlich erfüllt sind. Die Voraussetzungen der Demokratie sind daher von der rechtlichen Organisations- und Legitimationsfrage 
vorgeprägt, in ihrer Faktizität jedoch von dieser unabhängig. Demokratietheorie weist daher das Methodenproblem auf, wie weit die juristische Bestimmbarkeit reicht und wo der Bereich außerjuristischer Feststellungen beginnt. Kann das Recht diese Abgrenzung treffen? Darf das Recht diese Abgrenzungen treffen?

Es lassen sich zwei Grundpositionen ausmachen, in denen die Probleme und Voraussetzungen der Demokratietheorie prinzipiell unterschiedlich gelöst werden. Die erste Position sieht Volk als eine faktische Größe an. Ihr Gegenstand ist die Volkssouveränität. Sie argumentiert mit Kriterien, die auf die Ermittlung des Seins des Volkes gerichtet sind. Die zweite Position sieht Volk als eine normative Größe an. Ihr Gegenstand ist das verfassungsrechtliche Demokratieprinzip. Sie argumentiert mit Kriterien, die auf die Ermittlung eines legitimierenden Zurechnungszusammenhangs von Subjekt und Objekt gerichtet sind.

Beide Positionen treffen in der staatsrechtlichen Diskussion der Weimarer Republik aufeinander. Dabei war die Weimarer Demokratietheorie in zwei Richtungen gespalten: eine konstruktive, gegenstandserzeugende Richtung und eine deterministische, gegenstandsbestimmte Richtung. Beginnen wir mit letzterer.

\section{DIE GEGENSTANDSBESTIMMTE DEMOKRATIEKONZEPTION (CARL SCHMITT)}

Die gegenstandsbestimmte Richtung begreift demokratische Repräsentation nicht als Konstruktion, sondern als Abbildung. ${ }^{8}$ Der Parlamentarismus stellt keine Konstruktionsaufgabe zum Zwecke der Repräsentation des Volkes und der Ermittlung eines Volkswillens dar, sondern bezweckt eine Abbildung des präexistenten Volkes und seines ihm immanenten Willens. ${ }^{9}$ Anders gewendet: Das Demokratiesubjekt Volk wird als eine vorgegebene Größe wahrgenommen, der das Demokratieobjekt entsprechen müsse. Das Verhältnis beider zueinander ist dann kein Konstruktionsproblem, sondern ein Repräsentationsproblem. Volk wird als eine reelle Größe angesehen. Genauso reell soll der „Volkswille“ sein. Das Parlament wird nicht dazu benötigt, einen Willen des Volkes zu bilden, sondern den Willen des Volkes abzubilden. Dadurch entsteht eine Differenz zwischen dem „Volkswillen“ und dem Organwillen des Parlaments sowie eine Differenz zwischen den Repräsentanten und den Repräsentierten.

Gegenstandsbestimmte Demokratiekonzeption vertraten in der Weimarer Staatsrechtslehre zum Beispiel Carl Schmitt, Erich Kaufmann ${ }^{10}$ und Gerhard

8 Zur Abbildtheorie vgl. E.-W. Böckenförde, Demokratie und Repräsentation, in: ders., Staat Verfassung, Demokratie 1991 (1983), 379-405; ders., Der Begriff des Politischen als Schlüssel zum staatsrechtlichen Werk Carl Schmitts, in: ders., Recht, Staat, Freiheit, 1991 (1988), 344-366 (364f.); H. Hofmann/H. Dreier, Repräsentation, Mehrheitsprinzip und Minderheitenschutz, in: H.P. Schneider/W. Zeh (Hg.), Parlamentsrecht und Parlamentspraxis, 1989, 165-197 (167f.); C. Schönberger, das Parlament im Anstaltsstaat. Zur Theorie parlamentarischer Repräsentation in der Staatsrechtslehre des Kaiserreichs, 1997, 282-301, 318-335, 361-384.

${ }^{9} \mathrm{Zu}$ solchen Sichtweisen der Repräsentation als einem „deutschen Problem“ H. Hofmann, Repräsentation, 2. Aufl. 1990 (1974), 15-28; O. Lepsius, Artikel „Repräsentation“, in: Evangelisches Staatslexikon, 4. Aufl. 2006, 2036-2041.

10 E. Kaufmann, Zur Problematik des Volkswillens, Berlin 1931, hier zitiert nach dem Wiederabdruck in ders., Gesammelte Schriften Band III, 1960, 272-284. Zu Erich Kaufmann vgl. allgemein F. A. Frhr. v. d. Hedyte, Das rechtsphilosophische Anliegen Erich Kaufmanns, in: Um Recht und Gerechtigkeit. Festgabe für Erich Kaufmann, 1950, 103-121; R. Smend, Zu Erich Kaufmanns wissenschaftlichem Werk, in: ebd., 391-400; E. Castrucci, Tra Organicismo e „Rechtsidee“. Il pen- 
Leibholz. ${ }^{11}$ Konzentrieren wir uns stellvertretend auf die Formulierung, die Carl Schmitt der Demokratie gegeben hat.

\subsection{Substantielle Gleichheit}

Carl Schmitt definiert Demokratie als diejenige Staatsform, die dem Prinzip der Identität des konkret vorhandenen Volkes mit sich selbst als politischer Einheit entspricht. ${ }^{12}$ Demokratie sei die Identität von Herrscher und Beherrschten, Regierenden und Regierten, Befehlenden und Gehorchenden. ${ }^{13}$ Schmitt erläutert: Mit dem Wort Identität sei das Existentielle der politischen Einheit des Volkes bezeichnet zum Unterschied von irgendwelchen normativen, schematischen oder fiktiven Gleichheiten. Demokratie erfordere ein in sich gleichartiges Volk, das den Willen zur politischen Existenz habe. ${ }^{14}$ Die Vorstellung der Identität setzt bei Schmitt demnach voraus, dass Subjekt und Objekt vorgegeben sind, das Volk also eine reale Größe ist.

Wenn nach Schmitt der Demokratie die Aufgabe gestellt ist, die Identität der Regierenden mit den Regierten herzustellen, dann müssen das Parlament und sein Organwille nach dem Modell der identitären Demokratiekonzeption gleichfalls real sein. Diese reale Größe muss mit jener des Volkes übereinstimmen. Es zeichnet sich schon hier ein Spannungsverhältnis ab, das nicht überbrückt werden kann: Wie soll begriffslogisch der Kreis der Repräsentanten identisch sein mit dem Kreis der Repräsentierten? ${ }^{15}$ Widerspräche nicht jede körperschaftliche Repräsentation der Identität? Auf einer realen, empirischen Grundlage ist eine solche Identität zwischen Menschen nicht möglich. Daher läge es auf der Hand, gerade vor dem realen Hintergrund den Unterschied von Repräsentierten und $\operatorname{Re}^{-}$ präsentanten zum Ausgangspunkt der Überlegungen zu machen. Das aber tut

siero giuridico di Erich Kaufmann, 1984; M. Friedrich, Erich Kaufmann, Der Staat 26 (1987), 231-249; O. Lepsius, Die gegensatzaufhebende Begriffsbildung, 1994, 164-174, 344-354; P. Lerche, Erich Kaufmann, in: P. Landau/H. Nehlsen (Hrsg.), Große jüdische Gelehrte an der Münchener Juristischen Fakultät, 2001, 20-31; F. Degenhardt, Zwischen Machtstaat und Völkerbund. Erich Kaufmann (1880-1972), 2008; J. Rozek, Erich Kaufmann, in: P. Häberle/M. Kilian/H. A. Wolff (Hrsg.), Staatsrechtslehrer des 20. Jahrhunderts, 2. Aufl. 2018, 263-279.

11 G. Leibholz, Das Wesen der Repräsentation unter besonderer Berücksichtigung des Repräsentativsystems, 1929, hier zitiert nach ders., Die Repräsentation in der Demokratie, 1973 (Nachdruck der 3. unveränderten Auflage von 1966). Die Themen und Thesen werden in einer Verfallsperspektive auf die Weimarer Reichsverfassung in Anlehnung an Carl Schmitt erneut behandelt durch G. Leibholz, Die Auflösung der liberalen Demokratie in Deutschland und das autoritäre Staatsbild, 1933, 9-39. Zu Leibholz' Repräsentationslehre: H. Hofmann, Repräsentation, 2. Aufl. 1990 (1974), 17f., 24-26; M. Wiegandt, Norm und Wirklichkeit, 1995, 150-170; dort auch zur Biographie und dem wissenschaftlichen Gesamtwerk; H. H. Klein, Gerhard Leibholz: Theoretiker der Parteiendemokratie und politischer Denker, in: ders., Das Parlament im Verfassungsstaat, 2006, 561-577; A.-B. Kaiser (Hrsg.), Der Parteienstaat. Zum Staatsverständnis von Gerhard Leibholz, 2013; C. Starck, Gerhard Leibholz (1901-1982), in: P. Häberle/M. Kilian/H. A. Wolff (Hrsg.), Staatsrechtslehrer des 20. Jahrhunderts, 2. Aufl. 2018, 679-691.

12 C. Schmitt, Verfassungslehre, 1928, 223.

13 C. Schmitt, Verfassungslehre, 1928, 234; ebenso schon ders., Die geistesgeschichtliche Lage des heutigen Parlamentarismus, 2. Aufl. 1926, 35. Zur Identität von Volk, Staat und Verfassung bei Schmitt H. Hofmann, Legitimität gegen Legalität, 2. Aufl. 1992, 148-156.

14 C. Schmitt, Verfassungslehre, 1928, 235.

15 Zur Repräsentationslehre Schmitts vgl. H. Hofmann, Legitimität gegen Legalität, 4. Aufl. 2002, 150-157; ders., Repräsentation, 2. Auf. 1990 (1974), 18, 23-25. 
Schmitt nicht, sondern er postuliert diesen Unterschied ideell weg, obwohl er reell besteht. Schmitt wendet die reelle Differenz zwischen dem präexistent vorausgesetzten Volkswillen und dem Organwillen des Parlaments gegen die Idee der parlamentarischen Repräsentation. ${ }^{16}$

Schmitt jongliert mit einer konstruierten Ebenenvertauschung von Realität und Idealität. Seiner idealen Identität kann nämlich die reale Repräsentation nie gerecht werden, was er aber zugleich von ihr verlangt. Man hat den Eindruck, als ob der Widerspruch in die Schmittsche Definition der Demokratie bewußt eingebaut ist, um ihre Unvollkommenheit logisch deduzieren zu können.

Zur Begründung der Identitätsthese führt Schmitt die These an, Voraussetzung der Demokratie sei die substantielle Gleichheit. Sie schließe aus, dass zwischen Herrschen und Beherrschtwerden eine qualitative Verschiedenheit bestehe. ${ }^{17}$ Es handelt sich hierbei jedoch nur um ein Synonym zur Identitätsthese. Die Maßgabe der Identität wird als substantielle Gleichheit definiert, nicht aber begründet. Die Begründung liegt im Kriterium dessen, was die Substanz der Gleichheit ist. Das Problem wird hier nur verlagert: von der Substanz der Identität auf die Substanz der Gleichheit.

\subsection{Nicht repräsentierbare Substanz}

Entscheidend ist und bleibt, was mit Substanz gemeint ist. Das Spektrum der Repräsentation ist bei Schmitt auf den Kreis der substantiellen Gleichartigkeit $^{18}$ oder auf die Idee nationaler Einheit ${ }^{19}$ beschränkt. Die Repräsentation folgt einer vorgegeben Entität. Dieser Zusammenhang wird auch in der Überlegung Schmitts deutlich, das Wort Identität sei für die Definition der Demokratie deshalb brauchbar, weil es die umfassende, die Regierenden wie Regierten einschließende Identität des homogenen Volkes bezeichne. ${ }^{20}$ Substantielle Gleichheit, eben noch der Inbegriff der Identität, wird nun mit dem Begriff des homogenen Volkes umschrieben.

An dieser Stelle thematisiert Schmitt den Widerspruch, der schon oben aufgefallen war, überhöht diesen Widerspruch aber zugleich. Es kommt Schmitt nicht auf die reale Verschiedenheit der Repräsentierten und Repräsentanten an. Diese Verschiedenheit, sagt Schmitt, komme nicht in Betracht, „denn repräsentiert werden nicht die Regierenden, sondern die politische Einheit als Ganzes."21 Es geht Schmitt also gar nicht um die Repräsentation von Menschen, sondern das identitäre Abbilden einer existentiellen Substanz. In der politischen Einheit liegt die Souveränität, die über den Volksbegriff mit Demokratie identifiziert wird. 22

16 C. Schmitt, Verfassungslehre, 1928, 210. Vgl. auch ders., Politische Romantik, 2. Aufl. 1925, 127.

17.C. Schmitt, Verfassungslehre, 235.

18 Vgl. ebd., 237.

19 Vgl. ebd., 210, 212.

20 C. Schmitt, Verfassungslehre, 235.

${ }^{21}$ Ebd., 235.

22 Zur Souveränität der politischen Einheit vgl. C. Schmitt, Der Begriff des Politischen, 3. Aufl. 1933, 21f.; vgl. auch ders., Soziologie des Souveränitätsbegriffs und politische Theologie, in: 
Daraus leitet Schmitt ein identitäres Demokratieverständnis ab, das er als die eigentliche Form der Demokratie präsentiert. Die demokratische Identität beruhe auf der Vorstellung, dass alles, was es innerhalb des Staates an Betätigung staatlicher Macht gebe, innerhalb der substantiellen Gleichheit verbleibe. „Alles demokratische Denken bewegt sich mit klarer Notwendigkeit in Immanenzvorstellungen."23 Die Demokratie in der Definition Schmitts ist daher repräsentationsfeindlich, suggeriert aber zugleich die Notwendigkeit einer Repräsentation durch Identität. Es ist ein innerer Widerspruch in Schmitts Gedankengang eingebaut, der fallweise instrumentalisiert werden kann. Findet eine identitäre Repräsentation statt, bräuchte es keines Parlamentarismus; andere Organe könnten genauso gut identitär fungieren. Gibt es keine Identität zwischen Regierenden und Regierten im Sinne der substantiellen Existenz und politischen Einheit, verfehlt das Parlament die Aufgabe der Demokratie nach Schmitt. Das Parlament steht in dieser Theorie in einem Erwartungsdilemma, dem es nicht gerecht werden kann.

\subsection{Parlamentarisch nicht erfüllbare Erwartungen}

Schmitt konfrontiert die Demokratie mit Erwartungen, die ein Parlament nie erfüllen kann. Dass es bei der auf die Verfassung gerichteten Volkssouveränität und bei dem auf das Verfassungsgesetz gerichteten Demokratieprinzip und der Repräsentationslehre um unterschiedliche Volksbegriffe und unterschiedliche Legitimationszusammenhänge geht, wird von Schmitt retuschiert. ${ }^{24}$ Schmitt vermengt Demokratie und Volkssouveränität, was auch durch seine Dichotomie von Verfassung und Verfassungsgesetz erklärlich wird. Das Verfassungsgesetz ist an der volkssouveränen Legitimation der Verfassung zu messen, der es aber nicht mehr gerecht werden kann. In seiner Abhandlung zur „geistesgeschichtlichen Lage des heutigen Parlamentarismus“ hat Schmitt die von seinen Prämissen leicht deduzierbaren Vorwürfe gegen den Parlamentarismus umgesetzt und Parlamentarismus in einen prinzipiellen Gegensatz zur Demokratie gebracht. ${ }^{25}$

Die Demokratiekonzeption Schmitts negiert die Differenz von Legitimationssubjekt und -objekt; Demokratie ist ihm vielmehr die Aufhebung dieser Differenz. Dadurch wird eine Repräsentationstheorie, die von der Vorstellung ausgeht, dass das Volk durch Vertreter repräsentiert werden müsse, bei Schmitt als eine halbherzige, wenn nicht sogar im Grunde undemokratische Form stigmatisiert. Alle Repräsentationsmodelle müssen hinter dem Maximum der Identität des homogenen Volkes zurückbleiben. Für die Konstruktion oder Organisation eines Repräsentationsverhältnisses ist bei Schmitt daher genauso wenig Platz wie für die normative Bestimmung des Legitimationssubjektes Volk. Die Bestimmung all dieser Fragen wird einer konstruktionsresistenten Seins-Ebene zugewiesen. Die De-

Hauptprobleme der Soziologie, Erinnerungsgabe für Max Weber, Band II, 1923, 3-35; ders., Politische Theologie. Vier Kapitel zur Lehre von der Souveränität, 2. Aufl. 1934, mit der berühmten Formel, souverän sei, wer über den Ausnahmezustand entscheide (ebd., 11). Ferner in Opposition zu H. Kelsen, der den Souveränitätsbegriff verdrängte, ebd., 27-31.

23 C. Schmitt, Verfassungslehre, 237.

24 Vgl. ebd., 242.Siehe auch ders., Die Diktatur, 2. Aufl. 1928, 137-139 in Auseinandersetzung mit der Lehre vom pouvoir constituant und der daraus folgenden Notwendigkeit, das Volk selbst wieder zu einem Staatsorgan zu machen.

25 C. Schmitt, Die geistesgeschichtliche Lage des heutigen Parlamentarismus, 2. Aufl. 1926, 5, 13f., $30 f f$. 
termination dieser Seins-Ebene stellt die Weichen für die Ausgestaltung jener Identität substantieller Gleichheit von Regierten und Regierenden.

Die Demokratietheorie Schmitts widersetzt sich daher den oben aufgeworfenen drei Grundfragen, die die Demokratietheorie beantworten muss. Eine Relation muss nicht organisiert oder konstruiert werden, denn sie ist entweder als Identität vorhanden oder nicht existent. Subjekt und Objekt der Demokratie entstehen aus der Homogenität des Volkes, sind also rechtlicher Bestimmung weder fähig noch bedürftig. Es ist nicht die Rechtswissenschaft, sondern die Seinswissenschaft, die über diese Fragen entscheidet. Schmitt postuliert daher keine Demokratietheorie, sondern die Unterordnung unter eine verpflichtende Seinsordnung, die einen einheitlichen, existentiellen, substantiell gleichartigen Charakter hat. Entscheidend wird für ihn, und davon hängt die Überzeugungskraft seines Modells ab, worin diese Seinsordnung liegt und wie sie erkannt werden kann. Zu beiden Fragen kann die Demokratie bei Schmitt nichts beitragen, obwohl dieses genau Kernfragen des oben umrissenen Programms einer jeden Demokratietheorie sind.

\subsection{Schlussfolgerungen}

Die am Beispiel der Thesen von Schmitt - und ergänzend ließen sich auch Erich Kaufmann und Gerhard Leibholz heranziehen - erörterte Sicht setzt Volkssouveränität mit dem Demokratieprinzip gleich. Der Volkswille ist für sie eine Realität. Ein davon unabhängiger Organwille des Parlaments ist demokratisch defizitär. Repräsentation heißt abbilden, nicht erzeugen. Die Repräsentationsfunktion kann daher auch durch andere Repräsentanten als das Parlament wahrgenommen werden. Die Probleme der Demokratietheorie reduzieren sich auf den Begriff des Volkes. Fragen des Legitimationsobjekts und des Legitimationsverfahrens geraten in Vergessenheit. Auch innerhalb des Problems des Legitimationssubjekts herrscht eine juristisch unterkomplexe Sichtweise vor. Die Prämisse, beim Volk handele es sich um eine präexistente, der juristischen Betrachtung vorausliegende ideelle Seinsgröße verhindert, dass das Legitimationssubjekt zum Gegenstand staatsrechtlicher Erörterungen werden kann. Eher politische und philosophische Bekenntnisse treten an ihre Stelle und sichern die Ausgangsthese der Identität von (zwangsläufig vorrechtlich zu denkender) Volkssouveränität und einem Demokratieprinzip ab, das bewusst konstruktionsresistent sein soll.

Anders zusammengefaßt ließe sich sagen: Aufgrund der gegenstandsbestimmten Methode wird das Legitimationssubjekt Volk nicht normativ erfasst, sondern als eine vorgegebene Größe angesehen, in der Wert und Wirklichkeit, Natur und Geist, Realität und Idealität miteinander verbunden sind. Gefordert wird daher eine Seinswissenschaft, kein konstruktiver Normativismus. Die Rechtswissenschaft müsse sich als Seinswissenschaft verstehen, wenn das Volk als Subjekt der Demokratie ein Gegenstand des Rechts sein soll. Dadurch wird aber, neben der Fragwürdigkeit des seinswissenschaftlichen Zugangs in der Rechtswissenschaft, der Unterschied von Volkssouveränität und Demokratieprinzip verkannt. Statt Demokratietheorie wird Staatstheorie betrieben. Das verfassungsrechtliche Problem der Demokratietheorie wird auf das Legitimationssubjekt reduziert und um das Legitimationsobjekt sowie das Legitimationsverfahren verkürzt. Zugleich wird das Legitimationssubjekt als ein ontologisches Problem angereichert und mit philosophischen Wert und Wirklichkeitsfragen belastet. 


\subsection{Erklärungsansatz}

Wie lässt sich dieses Grundmuster erklären? Zum einen steht es in der Tradition des staatsrechtlichen Denkens im Kaiserreich. Auch das damalige Repräsentationskonzept fußte auf der Abbildtheorie. ${ }^{26}$ Diesem Verständnis verpflichtet konnte in der Auflösung des Reichstages durch den Reichspräsidenten die Wiederherstellung der demokratischen Repräsentation gesehen werden. ${ }^{27}$ Die Neuwahl des Reichstags ermöglichte es in dieser Sicht geradezu, den Volkswillen aufs Neue und zeitlich genau wiederzugeben: Es gibt einen wirklichen Gemeinwillen, dem sich das Recht durch seine Formen anzunähern versucht. ${ }^{28}$ Die Behandlung der repräsentativen Funktion des Parlaments stand daher durchaus in der Tradition der Argumentationslinien des Kaiserreichs. Der Unterschied zwischen dem Volk als Subjekt der Volkssouveränität und dem Volk als Subjekt des verfassungsrechtlichen Demokratieprinzips ist nicht etwa nicht gesehen worden, sondern die Differenz wird bewusst negiert und die Perspektive zugunsten einer Identität des Volkes als Subjekt der einen wie der anderen Kategorie ausgerichtet. Gerade der Zurückweisung einer dualen Subjektstellung des Volkes gilt ihr Bestreben. ${ }^{29}$

Sie kann dabei auch mit der neuen Verfassungslage unter der Weimarer Reichsverfassung argumentieren. Durch die WRV war es zur Auswechslung der Souveränitätsgrundlage gekommen. Nicht mehr die Monarchen waren Inhaber der Souveränität, sondern das Volk. Als wesentliche Neuerung durch die WRV musste daher die Einführung der Volkssouveränität empfunden werden mit der Folge, dass ihr vorrangige Geltung als der werthaften politischen Entscheidung zugebilligt werden konnte. Dadurch scheint die Volkssouveränität gerade zum verfassungsrechtlichen Zentralbegriff der jungen Demokratie geworden zu sein. Der Volkswille wird nicht nur Quelle des Staates, sondern fällt mit dem Staatswillen zusammen. ${ }^{30}$ Die neue Legitimationsgrundlage legte die Fusion von Volkswille, Staatswille und Organwille nahe.

Damit war eine politische Argumentation vorgezeichnet, in der man über das Mittel der Präeminenz der Volkssouveränität das verfassungsrechtliche Demokratieprinzip und die parlamentarische Repräsentation an einem substanzhaften Volksbegriff maß. Über einen verfassungsrechtlich nicht normierten, werthaften Volksbegriff konnte die WRV auf diese Weise mit ihren eigenen Waffen geschlagen

${ }^{26}$ Zur Dominanz der Abbildtheorie im Parlamentarismus-Verständnis des Spätkonstitutionalismus vgl. C. Schönberger, Das Parlament im Anstaltsstaat, 1997, 282-301, 318-335, 361-384.

27 Vgl. C. Schönberger, Das Parlament im Anstaltsstaat, 1997, 373-382 zu Hugo Preuß‘ Ansichten über die parlamentarische Repräsentation, 382f., 397-404, 410-412 zur Übertragung auf die WRV. Andere Deutung bei D. Lehnert, Verfassungsdemokratie als Bürgergenossenschaft. Politisches Denken, Öffentliches Recht und Geschichtsdeutungen bei Hugo Preuß, 1998, 107-123, 284-288, 292-299.

28 So C. Schönberger, Das Parlament im Anstaltsstaat, 1997, 377.

29 Vgl. zur negativen Grundeinstellung gegenüber dem Parlamentarismus und dem damaligen Drang, logische Widersprüche nachzuweisen und die parlamentarische Wirklichkeit an artifiziellen Idealen zu messen M. Stolleis, Geschichte des öffentlichen Rechts in Deutschland, Band 3, $1999,104 f$.

30 Vgl. C. Gusy, Die Lehre vom Parteienstaat in der Weimarer Republik, 1993, 60. Zum Fortwirken der konstitutionellen Doktrin in der Staatsrechtslehre der zwanziger Jahre auch H. Kelsen, Wesen und Entwicklung der Staatsgerichtsbarkeit, VVDStRL 5 (1929), 30-88 (33f.). 
werden: Die Verfassungsordnung gerät unter den Verdacht, im Verhältnis zur „wahren“ Volkssouveränität nur eine defizitäre demokratische Ordnung errichtet zu haben. Das Auswechseln der Souveränität vom monarchischen Prinzip zum Prinzip der Volkssouveränität ermöglichte es, argumentativ an der Abbildtheorie festzuhalten. Im Abbilden des vorrechtlichen, substanzhaften Volkswillens konnte das legitime Ziel der Demokratietheorie erblickt werden. Es ist ein gewissermaßen paradoxes Ergebnis, wie durch den Wandel in den Grundlagen des Verfassungsrechts antiparlamentarische Kontinuität bewahrt werden konnte. Theorien, die im Kaiserreich eher zur Abwehr der sich abzeichnenden Parlamentarisierung des Reiches dienten, empfanden sich durch die Suprematie der Volkssouveränität unter der WRV bestätigt.

Ein Erklärungsfaktor sind außerdem die philosophischen Grundüberzeugungen der Zeit. Mit dem Ziel der Überwindung der Trennung von Sein und Sollen war es zu einer Konjunktur neuer Philosophien gekommen, die ihre Aufgabe in der Verbindung von Natur und Geist, Wert und Wirklichkeit, Faktizität und Normativität sahen und behaupteten, über eine Methode zu verfügen, die dem Menschen die Erkenntnis dieser höheren Ebene erschließt. ${ }^{31}$ Von einem einheitlichen Volksbegriff auszugehen und nicht zwischen dem Volk als Subjekt der verfassunggebenden Gewalt und des verfassungsrechtlichen Demokratieprinzips zu unterscheiden, war dann nicht nur eine politische Notwendigkeit, sie entsprach nicht nur gleichermaßen der Tradition wie der Grundentscheidung für die Volkssouveränität durch die WRV, sondern sie durfte auch als philosophische Notwendigkeit angesehen werden. Die Umsetzung politischer und verfassungsrechtlicher Postulate der Volkssouveränität verband sich mit der Umsetzung neuer philosophischer Einsichten in die Struktur des Seins. Alle Differenzierungen und Trennungen innerhalb des Volksbegriffs konnten von der Warte höherer philosophischer Erkenntnis zurückgewiesen werden. Die Identifikation von Volkssouveränität und Demokratieprinzip erschien als angewandte moderne Philosophie. Auf diese Weise erklärt sich auch die erstaunliche Häufigkeit, mit der Staatsrechtler in jenen Jahren philosophische Bekenntnisse ablegten und ihre Abhandlungen mit Vorüberlegungen einleiteten, die sich an vorfabrizierte Philosophien anlehnten.

Die These des einheitlichen, wirklichen und ein „höheres Sein“ verkörpernden Volkes beruhte daher auch auf dem Aufkommen neuer philosophischer Richtungen. Ihre Rezeption ließ die staatsrechtlichen Beiträge nicht nur methodisch „auf der Höhe der Zeit" erscheinen und als modern erscheinen, sie ermöglichte es zugleich, der Argumentation einen entscheidenden Stein hinzuzufügen: die Überzeugung, dass aus Gründen der philosophischen Erkenntnis eine Aufteilung des Volkes widersinnig und künstlich ist. Wenn die juristische Erkenntnis den zeitgenössischen wissenschaftstheoretischen Prämissen Genüge leisten wolle, könne sie nicht auf eine rein rechtswissenschaftliche, gegenstandserzeugende Methode zurückgreifen, sondern müsse die gegenständlichen Fragen des aller juristischen Erkenntnis vorausliegenden Seins in ihre Betrachtung einbeziehen. Aus dieser Affizierung an zeitgenössische Seins-Philosophien erklärt sich auch das Postulat, einer "geisteswissenschaftlichen Methode“ folgen zu müssen, was immer dann im

$31 \mathrm{Zu}$ Darstellung und Einfluß der neuen Seinsphilosophien sowie ihrer Rezeption in der Rechtswissenschaft O. Lepsius, Die gegensatzaufhebende Begriffsbildung, 1994, insbes. 126ff., 219ff., 365ff.; T. Duve, Normativität und Empirie im öffentlichen Recht und der Politikwissenschaft um 1900, 1998, 212-231, 320-340. 
Einzelnen unter diesem Topos verstanden wurde. Die seinswissenschaftlich reduzierte Demokratietheorie wähnte sich in dem Bewußtsein, über eine neue Form der Erkenntnis eines „höheren Seins“ zu verfügen und gerade deswegen die neukantianische Erkenntnislehre überwinden zu können. ${ }^{32}$

Drei Grundlinien können daher für diese erste Richtung demokratischen Denkens in der Weimarer Republik verantwortlich gemacht werden: Politische Tradition der Abbildtheorie, verfassungsrechtliche Inthronisation der Volkssouveränität, philosophische Zwangsläufigkeit gegensatzaufhebender SeinsPhilosophien. In der Übertragung auf die Demokratietheorie führt dieses gedankliche Dreieck dazu, Volk als eine reale Größe anzuerkennen. Das Volk soll wirklich vorhanden sein; es ist konstruktionsresistent; ein Wille muss nicht erzeugt, sondern nur aufgespürt und abgebildet werden. Probleme der Artikulation und Intersubjektivität, der Mehrheitsbildung und des Minderheitenschutzes treten nicht in den Blick; das Volk steht nicht in einem Verhältnis zum einzelnen Individuum, sondern ist ein reeller Organismus. Es geht nicht um die Aggregation von Individuen. Das Volk wird nicht soziologisch wahrgenommen, sondern geistig überhöht. Repräsentation ist daher ein faktisches Problem, kein juristisches oder konstruktives. Die Probleme liegen allein beim Legitimationssubjekt und sind selbst dort auf eine Sichtweise (das Volk als Souverän) reduziert. Zwischen Volkswille, Organwille und Staatswille kann nicht differenziert werden. Volkssouveränität und Demokratietheorie werden gleichgesetzt oder nivelliert. Die parlamentarische Repräsentation wird am Ideal der Volkssouveränität gemessen und nicht als eine verfassungsrechtliche Ausgestaltungsaufgabe begriffen.

Hier liegt die Sprengkraft für das parlamentarische Modell von Weimar, das in eine Opposition zur "wahren“ Demokratie gebracht und als Verzerrung der Volkssouveränität stigmatisiert werden kann. Zugleich wird deutlich, warum Fragen nach der Gestaltung des Parlamentarismus in der staatsrechtlichen Diskussion der Weimarer Republik nur wenig erörtert wurden. ${ }^{33}$ Die Probleme von Volk und Volkswille waren auf einer grundsätzlicheren Ebene angesiedelt, die in der Annahme, der ideellen Wirklichkeit des Volkes nah zu sein, die wirklichen Aufgaben der staatsrechtlichen Demokratietheorie gar nicht erst behandelte. „Demokratietheorie" ist hier im Grunde kein Gegenstand der Rechtswissenschaft, sondern einer Seinswissenschaft. Um Themen der Demokratie behandeln zu können, soll die Staatsrechtslehre methodisch um die Ebene des Seins erweitert werden.

\section{DAS GEGENSTANDSERZEUGENDEN MODELL (HANS KELSEN)}

Ein konträres Modell der juristischen Demokratietheorie wurde in der Weimarer Republik vornehmlich durch Hans Kelsen entwickelt, ergänzend könnte man auf Richard Thoma ${ }^{34}$ und Karl Loewenstein ${ }^{35}$ verweisen. Ihr Ansatz stellt

$32 \mathrm{Zu}$ den philosophischen Hintergründen des Richtungsstreits im allgemeinen O. Lepsius, Die gegensatzaufhebende Begriffsbildung, 1994; ders., Erkenntnisgegenstand und Erkenntnisverfahren in den Geisteswissenschaften der Weimarer Republik, Ius Commune 22 (1995), 283-310.

33 Ebenso M. Stolleis, Geschichte des öffentlichen Rechts in Deutschland, Band 3, 1999, 103108; M. Friedrich, Geschichte der deutschen Staatsrechtswissenschaft, 1997, 386-390; siehe auch C. Gusy, Die Lehre vom Parteienstaat in der Weimarer Republik, 1993, 83-85, 94-96.

34 Thomas Schriften sind gesammelt herausgegeben von H. Dreier: R. Thoma, Rechtsstaat Demokratie - Grundrechte, 2008. Darin vor allem: Der Staatsbegriff der modernen Demokratie in seinem Verhältnis zum Staatsbegriff (1922); Sinn und Gestaltung des deutschen Parlamentarismus (1929); Das Reich als Demokratie (1930). Zu Thoma vgl. H.-D. Rath, Positivismus und De- 
sich in nahezu jeder Hinsicht als das Gegenmodell zum gegenstandsbestimmten Vorgehen dar. Es soll hier als die gegenstandserzeugende Demokratietheorie bezeichnet werden. ${ }^{36}$ Volk ist für sie als verfassungsrechtliche Kategorie keine präexistente Realität. Aus der faktischen Vielgestaltigkeit des Volkes folge für das Recht gerade die Aufgabe, die Willensbildung des Volkes zu organisieren. In dieser Perspektive verschiebt sich die Bewertung des Parlamentarismus: Das Parlament kann nicht mehr an einem prädeterminierten Volkswillen gemessen werden, sondern ist eine konstitutive Voraussetzung dafür, dass das Volk überhaupt zu einem leistungsfähigen Legitimationssubjekt werden kann. Das gegenstandserzeugende Modell muss daher auch zwischen der Volkssouveränität und dem verfassungsrechtlichen Demokratieprinzip trennen.

\subsection{Die Demokratietheorie als Komplementär zur Reine Rechtslehre}

Die elaborierteste Demokratietheorie aus dem Kreise der Weimarer Staatsrechtslehrer stammt von Hans Kelsen. Auf sie will ich mich daher hier konzentrieren und greife dafür vor allem auf Kelsens „Allgemeinen Staatslehre“ aus 1925 zurück. Kelsens Staatslehre hatte eine enorme zeitgenössische Wirkung. Sie löste die Gegenentwürfe von Schmitt („Verfassungslehre“) und Smend („Verfassung und Verfassungsrecht“) aus. ${ }^{37}$ Ganz unabhängig, wie man zur „Reinen Rechtslehre" steht, liefert Kelsens Demokratietheorie jedenfalls eine wichtige rechtserzeugende Komplementärfunktion zu seiner Normtheorie. Kelsens Demokratietheorie

mokratie. Richard Thoma 1874-1957, 1981; H. Dreier, in: ders. (Hrsg.), Richard Thoma, Rechtsstaat - Demokratie - Grundrechte, 2008, XIX-LXXXI; K. Groh, Demokratische Staatsrechtslehrerin der Weimarer Republik, 2010, 70-106; dies., Richard Thoma, in: P. Häberle/M. Kilian/H. A. Wolff (Hrsg.), Staatsrechtslehrer des 20. Jahrhunderts, 2. Aufl. 2018, 183-195; H. Döring, Der Weimarer Kreis. Studien zum politischen Bewußtstein verfassungstreuer Hochschullehrer, 1975; W. Heun, Der staatsrechtliche Positivismus in der Weimarer Republik, Der Staat 28 (1989), 377404 (385-388); W. Pauly, Die neue Sachlichkeit der Staatsrechtslehre in der Demokratie, in: Anschütz/Thoma, Handbuch des Deutschen Staatsrechts (1930/1932), Neuausgabe 1998, 3*-17*.

35 Schriften K. Loewensteins aus der Zeit der Weimarer Republik: Volk und Parlament nach der französischen Nationalverfassung von 1789, 1922; Erscheinungsformen der Verfassungsänderung, 1931. Später vor allem: Verfassungslehre, 1959, 4. Aufl. 2000. Loewenstein beschäftigte sich in den 1920er Jahren intensiv mit dem Verfassungsrecht in Großbritannien, das er dem deutschen Leser als Vorbild vor Augen führte; vgl. etwa Zur Soziologie der parlamentarischen Repräsentation in England, in: Archiv für Sozialwissenschaften und Sozialpolitik 51 (1924), 614708; Verfassungsleben in Großbritannien, in: JöR 20 (1932), 195-319. Zu Loewenstein vgl. M. Lang, Karl Loewenstein. Transatlantischer Denker der Politik, 2007; R. C. van Ooyen (Hrsg.), Verfassungsrealismus. Das Staatsverständnis von Karl Loewenstein, 2007; O. Lepsius, Karl Loewenstein (1891-1973), in: P. Häberle/M. Kilian/H. A. Wolff (Hrsg.), 2. Aufl. 2018, 489-517.

36 Vgl. H. Kelsen, Allgemeine Staatslehre, 1925, 369: Demokratie als Methode, eine soziale Ordnung zu erzeugen; ähnlich ders., Vom Wesen und Wert der Demokratie, 2. Aufl. 1929, 14, 94, 98.

37 Weitere wichtige Schriften Kelsens zur Demokratie aus den zwanziger Jahren sind: Vom Wesen und Wert der Demokratie, 1920 (38 Seiten), hier zitiert nach der auf 119 Seiten ergänzten 2. Aufl. 1929; Das Problem des Parlamentarismus, 1925 (44 Seiten), hier zitiert nach dem Wiederabdruck bei F. Koja (Hg.), Hans Kelsen oder die Reinheit der Rechtslehre, 1988, 161-191; Demokratie. Verhandlungen des 5. Deutschen Soziologentages vom 26. Bis 29. September 1926 in Wien, 1927, 37-68, 113-118. Die Allgemeine Staatslehre aus 1925 bündelt diese Schriften. Eine Zusammenstellung von Kelsens wichtigsten demokratietheoretischen Schriften bei: Hans Kelsen, Verteidigung der Demokratie, 2006 (hrsg. v. M. Jestaedt/O. Lepsius). 
müsste daher geeignet sein, Verdikte gegen das Werk Kelsens abzubauen. ${ }^{38}$ Der Einfluß der Rechtswissenschaft auf die materielle Gestaltung des Rechts ist bei ihm weitgehend reduziert, damit der Wille der demokratischen Rechtsetzungsorgane möglichst unverfälscht zur Geltung kommen kann. ${ }^{39}$ Die Demokratietheorie Kelsens übernimmt die Funktion der Rechtserzeugung, ${ }^{40}$ wovon seine Rechtslehre als rein normative Theorie gerade absieht. Kelsens Demokratietheorie aber kann Realvoraussetzungen einbeziehen, die aus der Reinen Rechtslehre bewußt ausgeklammert werden. Allein durch diese Aufteilung muss die Demokratie bei Kelsen herausragendes Gewicht bekommen. Sie erzeugt die Substanz, mit der sich die normative Rechtslehre beschäftigt. Schon hier deutet sich die Opposition zu den gegenstandsbestimmten Modellen an, die diese beiden Ebenen zu verbinden pflegten. Die Trennung zwischen demokratietheoretischer Rechtserzeugung und normtheoretischer Rechtsanwendung hingegen ermöglicht es Kelsen, Postulaten der Werturteilsfreiheit und Einsichten der gegenstandserzeugenden Erkenntnistheorie gerecht zu werden. Gerade weil er keinem substanzhaften, von dem jeweiligen existentiellen Sein geprägten Volks- und Demokratiebegriff anhing, vermochte Kelsen zeitunabhängige Einsichten in die Wirkungsweise und die Voraussetzungen der Demokratie zu formulieren.

\subsection{Trennung von Souveränität und Demokratie}

Kelsen trennt deutlicher als jeder andere zwischen der Souveränitätsfrage und dem Demokratieprinzip. ${ }^{41}$ In der Demokratie stellt sich die Souveränitätsfrage für ihn nicht mehr. Er erhebt sie zu einem Problem des Völkerrechts, ermöglicht dadurch ihre Verrechtlichung ohne den der Verfassung vorrangigen Geltungsgrund auf diese Weise auszuschließen. Wenn der Staat als Rechtsordnung verstanden wird, dann kann auch die Souveränitätsfrage nicht faktisch, sondern nur rechtlich über den Geltungsvorrang des Völkerrechts gelöst werden. Das ideologische Potential der Lehre von der Volkssouveränität wird auf diese Weise

38 Vgl. vor allem H. Dreier, Rechtslehre, Staatssoziologie und Demokratietheorie, 2. Aufl. 1990, 249ff., 278ff.; vgl. auch M. Jestaedt, Hans Kelsens Reine Rechtslehre. Eine Einführung, in: Hans Kelsen, Reine Rechtslehre. Studienausgabe der 1. Auflage 1934, 2008, XI (XL ff.); M. Jestaedt, Ein Klassiker der Rechtstheorie. Die „Reine Rechtslehre“ aus dem Jahre 1960, in: H. Kelsen, Reine Rechtslehre. Studienausgabe der 2. Auflage 1960, 2017, XII ff.; R. C. van Ooyen, Der Staat der Moderne. Hans Kelsens Pluralismustheorie, 2003; ders., Hans Kelsen und die offene Gesellschaft, 2. Aufl. 2017.

39 So H. Dreier, 281, 286: Die Reine Rechtslehre ist die der Demokratie adäquate Rechtstheorie, weil sie dem demokratisch legitimierten Willen der Mehrheit keine unverfügbaren Rechtsprinzipien verordnet. Vgl. auch M. Jestaedt/O. Lepsius, Der Rechts- und der Demokratietheoretiker Hans Kelsen, in: dies. (Hrsg.), Hans Kelsen, Verteidigung der Demokratie, 2006, VII-XXX; siehe auch M. Jestaedt, Der Staatsrechtslehrer Hans Kelsen - Provokateur aus Leidenschaft, in: ders. (Hrsg.), Hans Kelsen und die deutsche Staatsrechtslehre, 1-10; U. Lembke, Weltrecht - Demokratie - Dogmatik. Kelsens Projekte und die Nachwuchswissenschaft, ebd., 223-240.

40 Vgl. den Begriff der „Erzeugungsmethoden“, den Kelsen im Zusammenhang mit der Demokratie verwendet, Allgemeine Staatslehre, 1925, 320; zu Gesetzgebung und Vollziehung als zwei Stufen des Prozesses der Rechtserzeugung ders., Wesen und Entwicklung der Staatsgerichtsbarkeit, VVDStRL 5 (1929), 30-88 (31).

41 H. Kelsen, Das Problem der Souveränität und die Theorie des Völkerrechts, 1920, 2. Aufl. 1928, insbes. §§ 9f., 21, 39, 42, 51; ders., Allgemeine Staatslehre, 1925, 103-115, 121-128 (zur Souveränitätslehre insbes. im Völkerrecht), sowie 313-315 (zu Fiktionen bei der Lehre von der Volkssouveränität bei der Repräsentation, „Dogma der Volkssouveränität“); ders., Vom Wesen und Wert der Demokratie, 2. Aufl. 1929, 30-33. 
neutralisiert und einer juristischen Behandlung zugänglich gemacht. ${ }^{42}$ Die Demokratietheorie Kelsens hat sich auf diese Weise von der Vermischung mit Souveränitätsfragen befreit. ${ }^{43}$ Das ermöglicht es Kelsen, die faktischen Umstände und die gesellschaftlichen Bedingungen der Demokratie klarer in den Blick zu nehmen. Der Ausgangspunkt seiner Demokratietheorie ist ein soziologischer, der Bezugspunkt ein juristischer.

Aus Kelsens Souveränitätstheorie folgt, dass es keinen Staatswillen geben kann, der vom Willen der staatlichen Organe unabhängig sein kann. Staatswille und Organwille fallen zusammen. Die Organe als Repräsentanten des Staates sind nötig, damit der Staat überhaupt einen Willen äußern kann. ${ }^{44}$ Wenn es keinen natürlichen, präexistenten Willen gibt und zur Willensbildung Organe und Repräsentanten notwendig sind, dann lassen sich für Kelsen Repräsentation und Organschaft nur als rechtliche Zurechnung konstruieren. ${ }^{45}$ Folglich ist ein Repräsentationsorgan nötig, damit der Repräsentierte die gewünschte Rechtswirkung durch eine Willensäußerung herbeizuführen vermag, die er selbst faktisch nicht setzen kann. ${ }^{46}$ Bei der Repräsentation des Volkes durch das Parlament handelt es sich um eine Fiktion, ${ }^{47}$ weil es schon keinen Volkswillen gibt, der repräsentiert werden könnte, sondern die Repräsentation nötig ist, um überhaupt einen Willen zu bilden. „Die Fiktion der Repräsentation soll den Parlamentarismus vom Standpunkt der Volkssouveränität legitimieren.“48

\subsection{Volk und Parlament als unabhängige Staatsorgane}

Kelsen kann den Parlamentarismus weder über die Volkssouveränität noch als Repräsentation rechtfertigen. Beides sei weder theoretisch noch realistisch durchzuführen. Volk und Parlament werden nicht unter dem Leitbild der Identität zueinander in Beziehung gesetzt, sondern voneinander getrennt belassen. Kelsen spricht von der Unabhängigkeit des Parlaments vom Volk. ${ }^{49}$ Volk und Parlament sind unterschiedliche Staatsorgane, deren Verhältnis darin besteht, dass das eine das andere zu wählen habe. Der Wille des Parlaments wird also dem Staat zugerechnet, kann aber nicht als Wille des Volkes gelten. Das Parlament bildet einen eigenen Willen als Organwillen in Vertretung des Volkes, das nicht in der Lage ist, als Staatsorgan einen Willen zu bilden. Die Beziehung des Volkes zum Parlament ist die eines Kreationsorgans unter dem Aspekt der sozialtechni-

42 Vgl. H. Kelsen, Das Problem der Souveränität und die Theorie des Völkerrechts, 15f.; ders., Allgemeine Staatslehre, 1925, 113-115; ders., Vom Wesen und Wert der Demokratie, 2. Aufl. 1929, 30f.

43 Vgl. H. Kelsen, Allgemeine Staatslehre, 1925, 314.

44 Vgl. H. Kelsen, Allgemeine Staatslehre, 1925, 310.

45 Ebd., 310f. mit Analogie zur zivilrechtlichen Stellvertretung.

46 Vgl. ebd., 312.

47 Ebd., 313, 315, 344.

48 H. Kelsen, Vom Wesen und Wert der Demokratie, 2. Aufl. 1929, 30f.

49 H. Kelsen, Allgemeine Staatslehre, 314. Ähnlich ders., Vom Wesen und Wert der Demokratie, 2. Aufl. 1929, $28 f$. 
schen Vorteile der Arbeitsteilung. 50 Wer hingegen im Verhältnis des Volkes zum Parlament mehr als ein Rechtsverhältnis sehe, wolle unter Vorspiegelung fiktiver repräsentativer Erwartungen ein weiteres Fortschreiten der demokratischen Entwicklung hemmen und hege eine politische Tendenz. ${ }^{51}$

Die Unterschiede zu dem gegenstandsbestimmten Ansatz treten hier deutlich hervor und könnten nicht größer sein. Bei Kelsen gibt es keinen Volkswillen als Seinsgröße. Er kritisiert, dass Person und Wille gleichgesetzt werden. Während die Person real sei, sei der Wille keine reale, sondern eine psychische Größe. ${ }^{52}$ Wären beide real, wäre die Person unfrei, denn der Wille wäre determiniert. Die Freiheit des Individuums verlangt danach, nicht von einem realen, prädeterminierten Volkswillen auszugehen. Der demokratische Wille muss formiert werden, damit sich das Individuum frei entfalten kann. Nur die Demokratie gewährleistet für Kelsen die Freiheit des Individuums: „Der freie Staat ist jener, dessen Form die Demokratie ist, weil der Wille des Staates oder die Rechtsordnung von denjenigen selbst erzeugt wird, die dieser Ordnung unterworfen sind."53 Anders als Carl Schmitt fundiert Kelsen die Demokratie also nicht in der (substantiellen) Gleichheit, sondern in der individuellen Freiheit.

Von der Notwendigkeit der freien Willensbildung aus betrachtet kann Kelsen auf der Ebene des Seins eine Reihe von Voraussetzungen ausmachen, die für die Funktionsfähigkeit der Demokratie erfüllt sein müssen. Tatsächliche Voraussetzungen für die gegenseitige Verständigung der an der sozialen Willensbildung Beteiligten müssen erfüllt sein. Kelsen nennt insbesondere eine kulturell relativ homogene Gesellschaft und eine gleiche Sprache. ${ }^{54}$ Seine Ausführungen wirken hier besonders aktuell und beweisen, dass Kelsen soziale Umstände zwar zum Zwecke der genuin juristischen Erkenntnis ausschloss, keineswegs aber als Wirkungsfaktoren aus den Augen verlor. Wenn man sich die sozialen Machtverhältnisse ansehe, sei die parlamentarisch-demokratische Staatsform der „wahre“ Ausdruck der gespaltenen Klassengesellschaft. Sie ermögliche es auch, gesellschaftliche Gegensätze friedlich und allmählich auszugleichen und nicht auf blutigem, revolutionären Wege zu überwinden. ${ }^{55}$ Demokratie lässt sich dann als ein Erkenntnisverfahren verstehen, das auf die Erzeugung von Gegenständen gerichtet ist und das Kommunikationsproblem der Gruppenbildung löst.

50 Vgl. H. Kelsen, Allgemeine Staatslehre, 314f.; 344; auf den Gedanken der Arbeitsteilung kommt Kelsen auch zur Rechtfertigung der Gewaltenteilung zurück, 362. Ebenso ders., Vom Wesen und Wert der Demokratie, 2. Aufl. 1929, $29 \mathrm{f}$.

51 So H. Kelsen, Allgemeine Staatslehre, 316 f., 344. Auf die politische, antiparlamentarische Dimension hinweisend ders., Vom Wesen und Wert der Demokratie, 2. Aufl. 1929, 30-32, 94f.

52 H. Kelsen, Allgemeine Staatslehre, 1925, 322f.; 325 gegen die Vorstellung eines „geheimnisvollen Gesamtwillens“ und eine „geradezu mystische Gesamtperson“; siehe auch 344.

53 Ebd., 326. Zur Fundierung der Demokratie in der Freiheit auch ders., Vom Wesen und Wert der Demokratie, 2. Aufl. 1929, 3-13.

${ }^{54}$ H. Kelsen, Allgemeine Staatslehre, 324. Vgl. auch ders., Vom Wesen und Wert der Demokratie, 2. Aufl. 1929, 65f.

55 H. Kelsen, Allgemeine Staatslehre, 1925, 361. 


\subsection{Repräsentation als freiheitssichernder Zurechnungszusammenhang}

Kelsen ergänzt die soziale Begründung durch normative Argumente. Die Idee, dass das Parlament das Volk repräsentiere, sei nicht nur soziologisch undenkbar, sondern auch normativ nicht gewollt. Parlamentarische Verfassungsordnungen schlössen regelmäßig das Volk als solches von jeder Gesetzgebungsfunktion aus. Auch das freie Mandat des Abgeordneten lasse sich mit der Repräsentationstheorie nicht vereinbaren. ${ }^{56}$ Mit diesen beiden Verfassungsgrundsätzen des Parlamentarismus sei die Auffassung des Parlaments als eines Repräsentativorgans des Volkes unvereinbar. Daher könne der Theorie des Parlamentarismus nicht vorgeworfen werden, dass sie im Widerspruch zu ihrer Idee den Volkswillen nicht darstelle. Ein solches Ansinnen habe der Parlamentarismus nie gehabt und er könne es weder sozial noch normativ erheben: Nach der Durchschnittsverfassung parlamentarischer Demokratien gebe es einen Volkswillen rechtlich gar nicht und ein einheitlicher Volkswille sei auch sonst eine Schimäre. 57 Nur in einem normativen Sinne könne von einer Einheit des Volkes die Rede sein. ${ }^{58}$ Der Demokratie und dem Parlamentarismus liege gerade im Gegenteil eine kritisch-relativistische Ideologie zugrunde. Der objektive Sinn des kontradiktorisch-dialektischen parlamentarischen Verfahrens sei keineswegs die absolute Wahrheit, genauso wenig wie sein Ziel identitäre Repräsentation sei. Es geht um „die Erzielung einer mittleren Linie zwischen den Interessen der Majorität und der Minorität: das politische Kompromiß“.59

Diese theoretische Konzeptionalisierung der parlamentarischen Demokratie leitet dann Kelsens Erörterungen zur rechtlichen Ausgestaltung an: Fragen des Mehrheits- oder Verhältniswahlrechts, der Wahlkreiseinteilung, des technischen Wahlproporzes, einer zweiten Kammer, der Parlamentsorganisation, der Immunität der Abgeordneten, schließlich der Volksinitiative und des Referendums, berufsständischer Selbstverwaltungen, sowie Fragen der Gewaltenteilung und der Gesetzesvollziehung durch die Verwaltung. ${ }^{60}$ Kelsen ist daher nicht primär auf die Bestimmung des Volkes als des Legitimationssubjekts fixiert, sondern sein Problem ist die Herstellung eines Zurechnungszusammenhangs zwischen dem Volk und der Herrschaft, also das Verhältnis von Legitimationssubjekt und Legitimationsobjekt. Erörterungen des Wahlrechts, freien Mandats, der politischen Parteien, der Kompromißfindung und des Meinungskampfes, der Gesetzgebung und Gesetzesbindung der Verwaltung, bis hin zur Verfassungsgerichtsbarkeit ${ }^{61}$

56 Ebd., 344, zuvor schon 313-315.

57 Ebd., 358.

58 H. Kelsen, Vom Wesen und Wert der Demokratie, 2. Aufl. 1929, 15 f.

59 H. Kelsen, Allgemeine Staatslehre, 359; mit Rekurs auf den Gedanken der Arbeitsteilung und des Wettbewerbs. Zum Verhältnis von Majoritätsprinzip und Kompromiß auch ders., Vom Wesen und Wert der Demokratie, 2. Aufl. 1929, 53-58, 101; ders., Das Problem des Parlamentarismus (1925), in: F. Koja (Hg.), Hans Kelsen oder die Reinheit der Rechtslehre, 1988, 161-191 (164-166, 179-187).

60 Vgl. Allgemeine Staatslehre, 343-368.

61 Vgl. H. Kelsen, Wesen und Entwicklung der Staatsgerichtsbarkeit, VVDStRL 5 (1928), 30-87 (81); ders., Wer soll Hüter der Verfassung sein? (hrsg. v. R. C. van Ooyen), 2008; siehe dort auch: R. C. van Ooyen, Die Funktion der Verfassungsgerichtsbarkeit in der pluralistischen Demokratie und die Kontroverse um den „Hüter der Verfassung“, VII-XXIII; S.-P. Hwang, Rechtsanwendung in der pluralistischen Demokratie, in: Der Staat 46 (2007), 442-462. 
behandeln dieses Legitimationsverhältnis als ein demokratietheoretisches Problem. Beim gegenstandsbestimmten Ansatz reduziert sich hingegen Demokratietheorie auf die Problematik des Legitimationssubjekts während die Fragen der Ausgestaltung der Herrschaft weniger als demokratietheoretisches, sondern als rechtsstaatliches Problem angesehen werden. Kelsens Demokratietheorie ist ergebnisoffen, weil die Wertebene nicht behandelt wird, sondern es gerade das Ziel der Demokratie ist, die Werte zu schaffen, während für die andere Richtung die Demokratie wertgebunden ist und gerade am Abbilden der werthaften Ordnung gemessen wird. Das dahinterstehende Leitbild ist für Kelsen der demokratische Kompromiss, während es für Schmitt die souveräne Entscheidung ist.

\subsection{Schlussfolgerungen}

Die Unterschiede lassen sich vielleicht folgendermaßen schematisieren: konstruktives statt seinsfixiertes Vorgehen; gegenstandserzeugende statt gegenstandsbestimmte Methode; positivrechtliche und empirische Argumentation statt geistig-ganzheitlicher Betrachtungsweise; Erzeugungsbedürftigkeit des Willens (Willensbildung) statt Vorgegebenheit des Volkswillens; Unterscheidung von Staat, Volk, Organ statt deren Fusionierung; eine Demokratie, die auf das Organ bezogen ist, statt einer Volkssouveränität, die auf den Staat bezogen ist; Fundierung der Demokratie in der Freiheit statt der Gleichheit; Problemerweiterung auf das Verhältnis von Legitimationssubjekt und Legitimationsobjekt statt Reduzierung auf das Volk als Subjekt.

Für Kelsen lässt sich daher, ähnlich wie für Thoma, ein anderes Resümee ziehen als für Schmitt. Die Themen sind in beiden Fällen die gleichen, die Behandlung und die Lösungen jedoch grundverschieden. Kelsen und Thoma trennen Souveränität und Demokratie. Dieses ermöglicht ihnen eine Präzision der Demokratietheorie auf das verfassungsrechtliche Demokratieprinzip und zugleich eine Hervorhebung der - davon zu trennenden - sozialen Voraussetzungen des demokratischen Prinzips, während bei den zuerst behandelten Autoren diese Fragen prinzipiell zusammenfallen und dies als Ausdruck der Volkssouveränität gerechtfertigt wird. Kelsen ist in der Lage, die parlamentarische Repräsentation als ein juristisches Zurechnungsverhältnis zu begründen und dies nicht nur juristisch darzulegen, sondern auch noch als unabweisbare Konsequenz aus sozialen Gegebenheiten unter Beweis zu stellen. Der Volkswille kann bei ihm schon im Angesicht der politisch-gesellschaftlichen Lage nicht vorausgesetzt werden, genauso wenig wie die Idee der Repräsentation theoretisch vorausgesetzt werden dürfe. Beide sind nicht konstruktionsresistent, sondern konstruktionsbedürftig. Dadurch verschiebt sich die Thematik von der Frage des Legitimationssubjekts (das allein die Vertreter der ersten Richtung beschäftigte) auf die Zusammenhänge von Legitimationssubjekt und Legitimationsobjekt. Fragen des Wahlrechts, der Gewaltenteilung, der Parlamentsorganisation treten in den Blick, zwingen dann aber zum Verlassen der abstrakt-theoretischen Ebene und zur Hinwendung auf die von der Weimarer Reichserfassung vorgenommene Ausgestaltung des Demokratieprinzips.

Kelsen ist aufgrund eines realistischen Volksverständnisses gezwungen, konkreter zu argumentieren. Das zeigt sich nicht zuletzt darin, dass er den gesellschaftlichen Wertpluralismus und den Meinungskampf akzeptiert und als Voraussetzung der Demokratie ernst nimmt, während dieser bei Schmitt geradezu zu einer Verfallserscheinung identitärer Demokratievorstellungen degeneriert. 
Paradoxerweise pflegt gerade Kelsen vorgehalten $\mathrm{zu}$ werden, dass seine rein rechtswissenschaftliche Betrachtung die soziale Wirklichkeit ausblende, während die gegenstandsbestimmten Ansätze üblicherweise für ihre „Wirklichkeitsnähe“ gerühmt werden. Doch Kelsens selektierende Betrachtung kann die soziale Wirklichkeit gerade empirisch ernst nehmen, während die gegenstandsbestimmte Sichtweise die Realität zu einem Bestandteil der Idealität macht. Ihre Wirklichkeit ist eine philosophische Seinsordnung, keine empirische.

Kelsen beendet seine Demokratietheorie mit einem Abschnitt „Staatsform und Weltanschauung“. Dort benennt er die Unterschiede, die hier mit der Dichotomie von Gegenstandsbestimmtheit und Gegenstandserzeugung bezeichnet worden sind. Die entscheidende Frage sei, ob es eine Erkenntnis absoluter Wahrheit, eine Einsicht in absolute Werte gebe oder nicht. ${ }^{62}$ Der Glaube an absolute Wahrheiten und absolute Werte schaffe die Voraussetzung für eine metaphysische und religiös-mystische Weltanschauung. Wer aber absolute Wahrheit und Werte menschlicher Erkenntnis für verschlossen hält, müsse nicht nur die eigene sondern auch eine fremde, gegenteilige Meinung zumindest für möglich halten. Darum sei der Relativismus die Weltanschauung, die der demokratische Gedanke voraussetzt. ${ }^{63}$ Kelsen thematisiert hier, was schon im Laufe der obigen Werkanalysen betont worden war, nämlich dass die Wahrnehmung von Demokratie und Parlamentarismus in der Weimarer Zeit in erheblichem Maße von der erkenntnistheoretischen und philosophischen Grundhaltung geprägt wurde. Nicht zufällig konnte bei den Schriften von Schmitt (und das würde auch auf Kaufmann, Leibholz, aber auch Smend und Heller zutreffen) immer wieder die hintergründige Dominanz philosophischer Einsichten nachgewiesen werden. Sie sind die zentrale Weichenstellung, von der aus Demokratie und Parlamentarismus behandelt werden. Von daher mag es gerechtfertigt sein, die Weimarer Demokratietheorie trotz aller Differenzierungen im einzelnen, denen hier naturgemäß nur unvollkommen nachgegangen werden konnte, schematisch in zwei Lager zu spalten: das gegenstandsbestimmte Vorgehen versus das gegenstandserzeugende Modell. Auf diese beiden Grundprägungen lassen sich des weiteren die jeweils unterschiedlichen Vorstellungen und Erwartungen zu Volk und Volkswille, Demokratie und Repräsentation zurückführen.

\section{ZUSAMMENFASSUNG}

Als Fazit kann ein grundlegender Dissens in der Weimarer Staatsrechtslehre über die Demokratie festgestellt werden. Es treten sich zwei Modelle gegenüber, die das Thema aus ganz anderer politisch-sozialer, juristischer sowie erkenntnistheoretischer Haltung angehen. Gerade darin liegt die Vorbildlichkeit der Weimarer Debatte. Sie beweist, mit welchen Prämissen Demokratietheorie zwingend behaftet ist und zu welchen unterschiedlichen Positionen konsequent durchgehaltene konträre Prämissen führen. Sie zeigt auch, dass eine Behandlung der Demokratie ohne die Zuhilfenahme juristischer Kategorien auf einer eher politischphilosophischen Reflexionsebene stecken bleibt. In diesem Fall macht sich die verfassungsrechtliche Demokratietheorie stärker von außerjuristischen Vorstel-

62 H. Kelsen, Allgemeine Staatslehre, 1925, 368-371 (369). Ähnlich ders., Vom Wesen und Wert der Demokratie, 2. Aufl. 1929, 98-104.

63 H. Kelsen, Allgemeine Staatslehre, 1925, 370. Vgl. auch ders., Die philosophischen Grundlagen der Naturrechtslehre und des Rechtspositivismus, 1928, 60-65, 68-71. 
lungen und Weltanschauungen abhängig, als ihr lieb sein darf. An der Wechselbezüglichkeit von Volkssouveränität und verfassungsrechtlichem Demokratieprinzip festzuhalten, birgt für das Verfassungsrecht ein Legitimationspotential, das im guten wie im schlechten mit den Mitteln des Rechts nicht ermittelt und bewältigt werden kann. Die Verwirklichung der Demokratie am Ideal der Volkssouveränität messen zu wollen, heißt, der Idee der repräsentativen Demokratie nicht gerecht werden zu können.

Fecha de envío / Submission date: 25/04/2019

Fecha de aceptación / Acceptance date: 7/05/2019 